\title{
INFLUÊNCIA DA POSIÇÃO DE SEMEADURA NA GERMINAÇÃO, VIGOR E CRESCIMENTO DE PLÂNTULAS DE BACABINHA (Oenocarpus mapora Karsten - ARECACEAE) ${ }^{1}$
}

\author{
WALNICE MARIA OLIVEIRA NASCIMENTO ${ }^{2}$, MARIA SOCORRO PADILHA OLIVEIRA ${ }^{2}$ \\ JOSÉ EDMAR URANO CARVALHO ${ }^{2}$ E CARLOS HANS MÜLLER ${ }^{2}$
}

\begin{abstract}
RESUMO - A bacabinha (Oenocarpus mapora Karsten) é uma espécie de palmeira que cresce em touceiras de cinco a 12 indivíduos, nativa da Amazônia, podendo ainda ser encontrada em alguns países do norte da América do Sul e da América Central. Seu fruto é utilizado para fabricar refresco, sorvetes e cremes. Extraindo também, de seu estipe palmito, com excelentes características organolépticas e bom rendimento, devido a suas potencialidades essa espécie vem sendo estudada no sentido de domesticá-la. Com o objetivo de verificar o efeito da posição de semeadura na germinação, no vigor e no crescimento das plântulas, foi realizado o experimento, testando-se quatro posições de semeadura com três repetições em parcelas de 25 sementes, sendo instalado em delineamento inteiramente casualizado. Avaliou-se a percentagem, o tempo médio de germinação e o comprimento das plântulas. Os resultados indicaram que a germinação de sementes de bacabinha não foi afetada pela posição de semeadura, alcançando valores acima de $92 \%$, porém, quando as sementes foram postas para germinar com o poro germinativo voltado para a superfície e com a rafe na posição horizontal e voltada para cima, as sementes germinaram em menor tempo. O desenvolvimento inicial das plântulas de bacabinha foi afetado pela posição de semeadura.

Termos para indexação: semente recalcitrante, palmeira nativa, fruto da Amazônia.
\end{abstract}

\section{INFLUENCE OF THE SOWING POSITION ON THE GERMINATION, VIGOR AND SEEDLINGS GROWTH OF Oenocarpus mapora Karsten - ARECACEAE}

\begin{abstract}
Oenocarpus mapora Karsten it is a type of palm tree that is native in Amazonia. The fruit is used for manufacture of juice, ice creams and creams. With the objective to verify the effect of the sowing position on the germination, vigor and seedlings length, the present experiment was accomplished, being tested four sowing positions with three replicates with 25 seeds per parcels and installed in a completely randomized design. The results showed that the germination of Oenocarpus mapora, seeds was not affected by the sowing position, showing by values above to $92 \%$, however, the when seeds were placed to germinate with the germination pore gone back to the surface, they germinated in smaller time. The initial development of the seedling was influenced by the sowing position.
\end{abstract}

Index terms: recalcitrant seed, native palm, Amazon fruit.

\section{INTRODUÇÃO}

${ }^{1}$ Aceito para publicação em 30.12.2001; trabalho apresentado durante o XII Congresso Brasileiro de Sementes.

${ }^{2}$ Eng $^{\text {os }}$ Agr $^{\text {os }}$, MSc., Pesquisadores da Embrapa Amazônia Oriental, Laboratório de Ecofisiologia a Propagação de Plantas, Cx. Postal 48, 66017-970, Fone (91) 299-4500, Belém, PA, Brasil; e-mail: walnice@cpatu.embrapa.br; spadilha@cpatu.embrapa.br; urano@cpatu.embrapa.br
A bacabinha (Oenocarpus mapora Karsten) é uma espécie de palmeira que cresce em touceiras de cinco a 12 indivíduos, nativa da Amazônia, podendo ainda ser encontrada em alguns países do norte da América do Sul e da América Central (Cavalcante, 1992).

O fruto é utilizado para fabricar refresco, sorvetes e cremes. Extraindo-se também de seu estipe, palmito, com exce- 
lentes características organolépticas e bom rendimento quando comparado com o palmito do açaizeiro (Oliveira et al., 2000).

Devido a relativa importância econômica dessa palmeira na Amazônica, estudos recentes sobre a caracterização morfológica e genética vem sendo conduzidos. Contudo ainda, são raros os trabalhos com germinação dessa espécie. Estudos desenvolvidos com outras Arecáceas podem ser encontrados na literatura, como as observações feitas por Carvalho \& Müller (1998), que avaliaram a germinação de sementes de Bactris gasipaes Kunth. quanto aos níveis de tolerância do teor de água da semente. Martins et al. (1999) desenvolveram estudo semelhante com sementes de Euterpe oleracea Mart. Mendonça \& Araújo (1999) caracterizaram a morfologia da semente de Oenocarpus bacaba Mart. Carvalho et al. (1998) caracterizaram como hipogeal, o tipo de germinação e como criptocotiledonar a plântula de Oenocarpus mapora Karsten. Esses autores verificaram também a freqüência de sementes por endocarpo, que é a principal estrutura de propagação dessa espécie, constatando $100 \%$ dos endocarpos com apenas uma semente.

Martins et al. (1999) observaram o efeito da posição da semente no substrato e no crescimento de plântulas de Euterpe espiritusantensis Fernandes e verificaram que a germinação é mais rápida quando a semeadura é feita com o poro de germinação voltado para cima.

Com relação ao desenvolvimento da plântula, Belin \& Queiroz (1987) observaram torções na raiz primária, durante as primeiras etapas do processo germinativo de Euterpe edulis Mart. No início do desenvolvimento, a raiz primária sofre uma torção em relação ao eixo caulinar, propiciando o aparecimento de raízes adventícias. Esses sintomas, no entanto, não caracterizam anormalidades de plântulas. Porém, o desconhecimento dos efeitos que a posição de semeadura pode ter na morfologia das plântulas destas espécies, pode induzir a interpretações errôneas dos resultados do teste de germinação.

Assim, o trabalho teve por objetivo verificar o efeito da posição de semeadura na germinação, vigor e crescimento das plântulas de Oenocarpus mapora.

\section{MATERIAL E MÉTODOS}

Os frutos de Oenocarpus mapora foram colhidos na safra 2000-2001 de plantas estabelecidas no Banco de Germoplasma de bacada da Embrapa Amazônia Oriental, Belém, PA e transportados para o Laboratório de Ecofisiologia e Propagação de Plantas dessa instituição. $\mathrm{O}$ beneficiamento foi feito através da imersão em água à temperatura de $50^{\circ} \mathrm{C}$, com permanência dos frutos na água aquecida por 30 minutos. Em seguida foram despolpados, através da fricção contra uma peneira de malha de aço. No despolpamento foram removidos o epicarpo e o mesocarpo do fruto. A estrutura de propagação da bacabinha é o endocarpo com uma semente dentro (Carvalho et al., 1998).

A determinação do teor de água foi realizada após o despolpamento, utilizando-se o método da estufa a $105 \pm 3^{\circ} \mathrm{C}$ por 24 horas (Brasil, 1992), com duas amostras de dez sementes inteiras.

Foram estabelecidas quatro posições de semeadura do endocarpo em relação ao plano horizontal a superfície do substrato: PS (poro na superfície), PB (poro para baixo), RHC (rafe na horizontal e para cima), RHB (rafe na horizontal e para baixo), esquematizado na Figura 1.

Para avaliar o efeito dos tratamentos na qualidade da semente e no desempenho das plântulas, foram utilizados os seguintes teste: germinação - conduzido com três repetições de 25 sementes cada, em temperatura ambiente (aproximada-

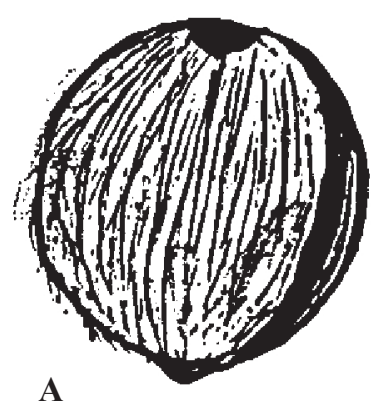

A
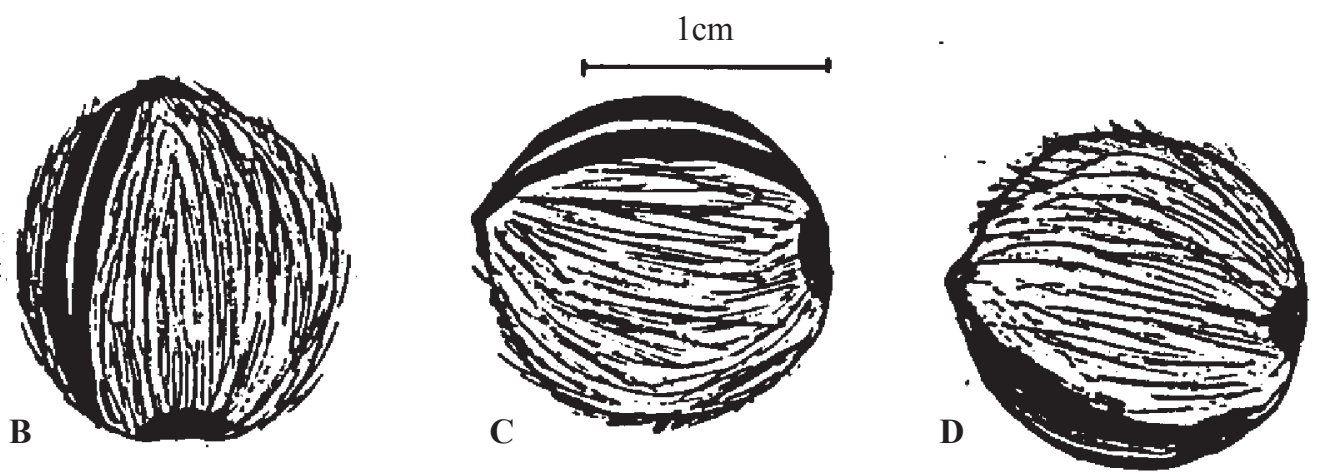

FIG. 1. Posição de semeadura: A - poro na superfície (PS); B - poro para baixo (PB); C - rafe na horizontal e para cima $(\mathrm{RCH})$; D - rafe na horizontal e para baixo (RHB). 
mente $26 \pm 3^{\circ} \mathrm{C}$ e $86 \%$ de umidade relativa do ar), utilizando como substrato mistura de areia e serragem, na proporção de $1: 1$, umedecido com água na quantidade equivalente a 2,5 vezes o peso do substrato seco. A contagem das plântulas foi realizada, diariamente, do $11^{\circ}$ ao $51^{\circ}$ dia após a semeadura; comprimento das plântulas - ao final do teste de germinação, foi avaliado o comprimento $(\mathrm{mm})$ da parte aérea (plúmula), da raiz primária e o total de plântulas normais; tempo médio de germinação - determinado por meio do critério estabelecido por Silva \& Nakagawa (1995), contabilizando-se diariamente as plântulas que emergiram após a instalação do teste de germinação. Esse índice representa a média ponderada do tempo necessário para a germinação, tendo como fator de ponderação a germinação diária, calculado pela equação:

$$
\mathbf{T m}=\frac{G_{1} T_{1}+G_{2} T_{2}+\ldots+G_{n} T_{n}}{G_{1}+G_{2}+\ldots+G_{n}}
$$

Onde: $\mathbf{T m}$ - é o tempo médio, em dias, necessário para atingir a germinação máxima; $\mathbf{G}_{1}, \mathbf{G}_{2}$ e $\mathbf{G}_{\mathrm{n}}$ é o número de sementes germinadas e nos tempos $\mathbf{T}_{1}, \mathbf{T}_{2}$ e $\mathbf{T}_{\mathrm{n}}$, respectivamente.

O delineamento experimental utilizado foi o inteiramente casualizado, com os tratamentos em três repetições. Foi efetuada a análise de variância, aplicando-se o teste $\mathrm{F}$ e fazendo-se a comparação das médias dos tratamentos pelo teste de Tukey, a $5 \%$ de probabilidade.

\section{RESULTADOS E DISCUSSÃO}

Os valores da percentagem e do tempo médio de germinação estão na Tabela 1. Por ocasião da instalação do experimento, as sementes apresentavam teor de água de 41,3\%. Observa-se que em todos os tratamentos, a germinação foi superior a 92\%. Carvalho et al. (1998) trabalhando com sementes de $O$. mapora com teor de água de $31,8 \%$ obtiveram índice mais baixo, $86 \%$ de germinação.

As três posições de semeadura testadas (PS, RHC e RHB) não diferiram entre si, podendo-se observar que quando as sementes foram postas para germinar com a rafe na horizontal para cima (RHC), 100\% das sementes germinaram. Apenas o tratamento (PB) poro voltado para baixo, diferiu estatisticamente dos demais tratamentos. Na Tabela 1, observase que quando as sementes foram postas para germinar com o poro germinativo voltado para a superfície (PS) e com a rafe na posição horizontal e voltada para cima (RHC), as sementes germinaram em menor tempo. Enquanto, Martins et al. 1999, avaliando o desenvolvimento das plântulas de $E$.
TABELA 1. Médias da percentagem e do tempo médio de germinação em sementes de bacabinha, colocadas em diferentes posições de semeadura.

\begin{tabular}{ccc}
\hline Posição de semeadura & $\begin{array}{c}\text { Germinação } \\
(\%)\end{array}$ & $\begin{array}{c}\text { Tempo médio } \\
(\text { dia })\end{array}$ \\
\hline PS & $97 \mathrm{a}$ & $15 \mathrm{c}$ \\
PB & $92 \mathrm{~b}$ & $27 \mathrm{a}$ \\
RHC & $100 \mathrm{a}$ & $15 \mathrm{c}$ \\
RHB & $97 \mathrm{a}$ & $21 \mathrm{~b}$ \\
\hline CV $(\%)$ & 1,69 & 9,67 \\
\hline
\end{tabular}

Médias seguidas pela mesma letra, na coluna, não diferem entre si pelo teste de Tukey, a $5 \%$.

PS - poro na superfície; PB - poro para baixo; RHC - rafe na horizontal para cima; RHB - rafe na horizontal para baixo.

espiritusantensis, verificaram que ela emergiu mais rapidamente, apenas, no tratamento em que o poro de germinação ficou mais próximo da superfície do substrato.

Os valores referentes ao comprimento da plúmula e da raiz primária estão relacionados na Tabela 2. Para o comprimento da raiz primária não houve diferença significativa entre os tratamentos testados. Contudo, a plúmula apresentou melhor desenvolvimento (13,29mm), quando a semeadura foi feita com o poro para baixo (PB). Não diferindo estatisticamente dos tratamentos PS e RHC. O comprimento da raiz primária foi maior no tratamento em que as sementes foram postas para germinar com a rafe na horizontal e voltada para cima $(15,75 \mathrm{~mm})$.

As sementes que foram postas para germinar com o hilo na superfície ou seja com o poro germinativo voltado para baixo, apresentaram baixa germinação e maior tempo médio

TABELA 2. Comprimento da plúmula e da raiz primária em plântulas de bacabinha, colocadas em diferentes posições de semeadura.

\begin{tabular}{|c|c|c|}
\hline Posição de semeadura & $\begin{array}{l}\text { Comprimento } \\
\text { raiz primária } \\
(\mathrm{mm})\end{array}$ & $\begin{array}{l}\text { Comprimento } \\
\text { plúmula } \\
(\mathrm{mm})\end{array}$ \\
\hline PS & $14,83 \mathrm{a}$ & $12,21 \mathrm{ab}$ \\
\hline PB & $15,33 \mathrm{a}$ & $13,29 \mathrm{a}$ \\
\hline RHC & $15,75 \mathrm{a}$ & $13,08 \mathrm{ab}$ \\
\hline RHB & 14,23 & 12,15 \\
\hline CV $(\%)$ & 3,88 & 3,33 \\
\hline
\end{tabular}

* Médias seguidas pela mesma letra, na coluna, não diferem entre si pelo teste de Tukey, a 5\%.

PS - poro na superfície; PB - poro para baixo; RHC - rafe na horizontal e para cima; RHB - rafe na horizontal e para baixo. 
de germinação. Algumas plântulas decorrentes da posição de semeadura apresentaram-se retorcidas, o mesmo tipo de deformação foi encontrado por Martins et al., 1999, em plântulas de Euterpe espiritusantensis quando as sementes foram postas para germinar com o poro germinativo voltado para baixo.

\section{CONCLUSÕES}

- Sementes de bacabinha não têm a germinação afetada nas quatro posições de semeadura testadas;

- para favorecer a emergência das plântulas de bacabinha, tornando-a mais rápida, a semeadura deve ser realizada com o poro de germinação voltado para a superfície do substrato;

- o desenvolvimento inicial das plântulas de bacabinha é afetado pela posição de semeadura.

\section{REFERÊNCIAS}

BELIN, M. \& QUEIROZ, M.H. Contribuição ao estudo ontogênico das palmeiras. Alguns aspectos da germinação de Euterpe edulis Mart. In: ENCONTRO NACIONAL DE PESQUISADORES EM PALMITO, 1, Curitiba, 1987. Resumos. Curitiba: Embrapa-CNPF, 1987. p.211-213. (Documentos, 19).

BRASIL. Ministério da Agricultura e da Reforma Agrária. Regras para análise de sementes. Brasília: SNDA/DNDV/CLAV, 1992. 365p.
CARVALHO, J.E.U. \& MÜLLER, C.H. Níveis de tolerância e letal de umidade em sementes de pupunheira Bactris gasipaes. Revista Brasileira de Fruticultura, Cruz das Almas, v.20, n.3, p.283-289, 1998.

CARVALHO, J.E.U.; NASCIMENTO, W.M.O. \& MÜLLER, C.H. Características físicas e de germinação de sementes de espécies frutíferas nativas da Amazônia. Belém: EmbrapaCPATU, 1998. 18p. (Boletim de Pesquisa, 203).

CAVAlCANTE, P.B. Frutas comestíveis da Amazônia. 5.ed. Belém: Edições CEJUP, CNPq Museu Paraense Emílio Goeldi, 1992. 279p

MARTINS, C.C.; NAKAGAWA, J. \& BOVI, M.L.A. Efeito da posição da semente no substrato e no crescimento inicial das plântulas de palmito-vermelho (Euterpe espiritusantensis Fernandes - Palmae). Revista Brasileira de Sementes, Curitiba, v.21, n.1, p.164-173, 1999.

MARTINS, C.C.; NAKAGAWA, J.; BOVI, M.L.A. \& STANGUERLIM, H. Teores de água crítico e letal para sementes de açaí (Euterpe oleraceae Mart. - Palmae). Revista Brasileira de Sementes, Curitiba, v.21, n.1, p.125-132, 1999.

MENDONÇA, M.S. \& ARAÚJO, M.G.P. A semente de bacaba (Oenocarpus bacaba Mart. - Arecaceae). Revista Brasileira de Sementes, Curitiba, v.21, n.1, p.122-124, 1999.

OLIVEIRA, M.S.P.; NAZARÉ, R.F.R. \& MOTA, M.G.C. Estudo comparativo da qualidade do palmito de bacabinha com o do açaizeiro. Belém: Embrapa Amazônia Oriental. 2000. 4p. (Comunicado Técnico, 39).

SILVA, J.B.C. \& NAKAGAWA, J. Estudo de fórmulas para cálculo da velocidade de germinação. Informativo ABRATES, Londrina, v.5, n.1, p.62-73, 1995. 